\title{
ZGOŠČENA PREDSTAVITEV SLOVARJEV IZGOVARJAV S KONČNIMI SUPER PRETVORNIKI
}

\section{Žiga GOLOB, Boštjan VESNICER, Jerneja ŽGANEC GROS, Mario ŽGANEC}

Alpineon d.o.o

\section{Simon DOBRIŠEK,}

Univerza v Ljubljani, Fakulteta za elektrotehniko

Golob, Ž., Vesnicer, B., Žganec Gros, J., Žganec, M., Dobrišek, S. (2016): Zgoščena predstavitev slovarjev izgovarjav s končnimi super pretvorniki. Slovenščina 2.o, 4 (1): 79-96.

DOI: http://dx.doi.org/10.4312/slo2.0.2016.1.79-96.

Računalniški modeli končnih pretvornikov omogočajo zgoščeno predstavitev slovarjev izgovarjav, ki jih uporabljajo tako sintetizatorji govora kot tudi razpoznavalniki govora. $\mathrm{V}$ članku je predstavljen nov tip končnih pretvornikov, t. i. končni super pretvorniki, s katerimi lahko slovarje izgovarjav predstavimo $\mathrm{z}$ manjšim številom stanj in prehodov kot z uporabo običajnih minimalnih determinističnih končnih pretvornikov. Predstavljen je učinkovit postopek gradnje končnih super pretvornikov, ki ohranjajo svojo determinističnost, poleg besed iz danega slovarja izgovarjav pa lahko sprejmejo in pretvorijo tudi nekatere druge besede, ki niso bile zastopane v izvirnem slovarju. Oddani izhodni fonetični prepisi za določene sprejete izvenslovarske besede so sicer lahko napačni, vendar se izkaže, da je napaka pri pretvorbi primerljiva z napakami, ki jih dosegajo trenutno najboljše metode za samodejno grafemsko-fonemsko pretvorbo besed za slovenski jezik. Za preizkus in preverjanje predlaganega postopka gradnje končnih super pretvornikov je bil uporabljen slovar izgovarjav SI-PRON za slovenski jezik, ki vsebuje več kot milijon različnih slovarskih vnosov. Rezultati poskusov so med drugim podali presenetljivo ugotovitev, da se velikost končnih pretvornikov z naraščanjem obsega slovarja prek določenega števila besed prične zmanjševati, kar pripisujemo predvsem velikemu številu pregibnih oblik besed v slovenščini.

Ključne besede: sinteza govora, slovar izgovarjav, končni pretvorniki 


\section{UVOD}

Modul za pretvorbo grafemskega zapisa besed $\mathrm{v}$ njihov fonetični prepis predstavlja enega izmed ključnih sestavnih delov sintetizatorja govora. Za samodejno določanje fonetičnega prepisa besed v slovenščini lahko uporabimo množici kontekstno odvisnih pravil, pri čemer moramo poznati mesto besednega naglasa (Gros in Mihelič, 1999). Ker je za slovenščino značilno prosto naglasno mesto, samodejno določanje besednega naglasa slovenskih besed ni popolnoma zanesljivo (Šef in Gams, 2004; Golob, 2009). Zato je za kvalitetno tvorjenje umetnega govora nujna uporaba obsežnih slovarjev izgovarjav besed oz. postopkov, ki se inherentno naučijo zakonitosti o izgovarjavi besed v postopku učenja na obsežnih slovarjih izgovarjav (Šef in Gams, 2004; Rojc in Kačič, 2007; Rojc in Mlakar, 2011).

Slovar izgovarjav predstavlja preslikavo grafemskih zapisov besed $\mathrm{v}$ njihove fonetične prepise. Za osnovne enote fonetičnih prepisov navadno uporabljamo alofone. Pri pregibno bogatih jezikih, kot je slovenščina, lahko slovarji izgovarjav vsebujejo tudi več milijonov slovarskih vnosov, zaradi česar je njihova uporaba v pomnilniško manj zmogljivih sistemih, kot so npr. vgrajeni sistemi, težavna. $\mathrm{V}$ teh primerih je nujna uporaba postopkov, ki omogočajo pomnilniško učinkovito zgoščeno predstavitev slovarjev izgovarjav.

V literaturi je mogoče zaslediti tri osnovne pristope, ki omogočajo zgoščeno predstavitev slovarjev izgovarjav, in sicer z uporabo oštevilčenih končnih avtomatov (Lucchesi in Kowaltowski, 1993; Daciuk in Piskorski, 2011), dreves predpon (Ristov, 2005) ter z uporabo končnih pretvornikov (Mohri, 1994; Golob at al., 2012). V članku bomo predstavili nov način zgoščene predstavitve slovarjev izgovarjav z uporabo t. i. končnih super pretvornikov, ki predstavljajo nadgradnjo običajnih končnih pretvornikov. Poleg bolj zgoščene predstavitve slovarjev v primerjavi z običajnimi končnimi pretvorniki lahko s končnimi super pretvorniki z razmeroma veliko točnostjo določimo alofonski prepis tudi številnim besedam, ki niso vsebovane $\mathrm{v}$ izvirnem slovarju. Tem besedam 
pravimo izven-slovarske besede (angl. out-of-vocabulary words).

V članku najprej na kratko predstavimo končne pretvornike ter prikažemo, kako lahko z njimi predstavimo slovar izgovarjav. Nadalje pokažemo, da zastopanost pregibnih oblik v slovarju močno vpliva na njihovo velikost (v smislu števila stanj in povezav med njimi). Sledi predstavitev t. i. končnih super pretvornikov, ki predstavljajo nov način predstavitve slovarjev izgovarjav, nazadnje pa podamo še rezultate predstavitve slovarja s takšnim pretvornikom, pri čemer ocenimo napako, ki jo naredimo, če z njim izvajamo grafemskoalofonsko pretvorbo besed, ki niso del izvirnega slovarja.

\subsection{Končni pretvorniki ter predstavitev slovarja izgovarjav}

Končne pretvornike (krajše KP) sestavljajo stanja ter prehodi med stanji. Vsak prehod ima vhodno in izhodno oznako. Ko se na vhodu KP pojavi določen vhodni niz, se ta nahaja v začetnem stanju. KP nato po vrsti sprejema vhodne simbole. Pri vsakem sprejetju vhodnega simbola odda izhodni niz simbolov, ki ga določa izhodna oznaka pripadajočega prehoda, ter se premakne v naslednje stanje. Če za poljuben vhodni simbol v trenutnem stanju ne obstaja prehod, ki ima vhodno oznako enako temu simbolu, pravimo, da KP vhodnega niza ne sprejema. Če se KP po prejetju vseh simbolov vhodnega niza nahaja v končnem stanju, pravimo, da vhodni niz sprejema, pri tem pa postane oddani izhodni niz veljaven. Omenimo še to, da je lahko vhodna ali/in izhodna oznaka enaka praznemu simbolu oziroma praznemu nizu.

KP, ki imajo v poljubnem stanju največ en prehod z določeno vhodno oznako, pravimo deterministični KP. Za takšne KP je hitrost pretvorbe vhodnega niza v izhodni niz visoka in ob primerni izvedbi odvisna samo od dolžine vhodnega niza. Druga prednost determinističnih KP je ta, da obstajajo učinkoviti algoritmi za njihovo minimizacijo. Tako dobimo minimalni KP, ki ima najmanjše število prehodov in stanj med vsemi ekvivalentnimi KP (Mohri, 1997), torej KP, ki za poljuben sprejet vhodni niz oddajo enak izhodni niz. 


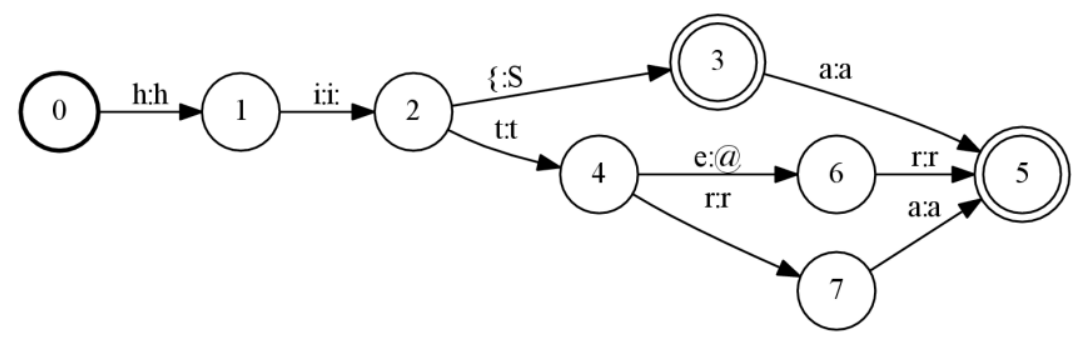

Slika 1: Primer končnega pretvornika, ki predstavlja slovar izgovarjav za štiri slovenske besede.

Vseh KP ni mogoče determinizirati, saj imajo deterministični KP manjšo izrazno moč kot nedeterministični (Hellis, 2004). KP, ki predstavlja slovar izgovarjav, lahko vedno determiniziramo, če iz slovarja odstranimo enakopisnice. Slika 1 prikazuje primer minimiziranega in determiniziranega KP (kratko MDKP), ki predstavlja slovar za štiri slovenske besede. Krogi predstavljajo stanja, puščice pa prehode med stanji. Vsak prehod je označen z vhodno in izhodno oznako, ki sta ločeni z dvopičjem. Začetno stanje je označeno z odebeljenim krogom, končna stanja pa z dvojnim krogom.

\section{VELIKOST KONČNIH PRETVORNIKOV}

V prvem poskusu smo želeli preveriti odvisnost velikosti KP od velikosti slovarja, ki ga želimo z njim predstaviti. Na voljo smo imeli slovar SI-PRON za slovenski jezik, ki vsebuje več kot milijon različnih slovarskih vnosov (ŽganecGros in dr., 2006). Z naključnim izbiranjem slovarskih vnosov smo zgradili 11 podslovarjev različnih naraščajočih velikosti in za vsak podslovar zgradili minimizirani in determinizirani končni pretvornik (MDKP). Rezultate v smislu števila stanj in prehodov pridobljenih MDKP prikazuje graf na sliki 2, pri čemer so vnosi v slovar izbrani naključno iz prvotnega slovarja.

Iz rezultatov lahko razberemo, da velikost MDKP doseže vrh pri 70 \% do $80 \%$ velikosti celotnega prvotnega slovarja. $\mathrm{Z}$ drugimi besedami, velikost MDKP 
začne pri določeni velikosti z dodajanjem novih besed padati.

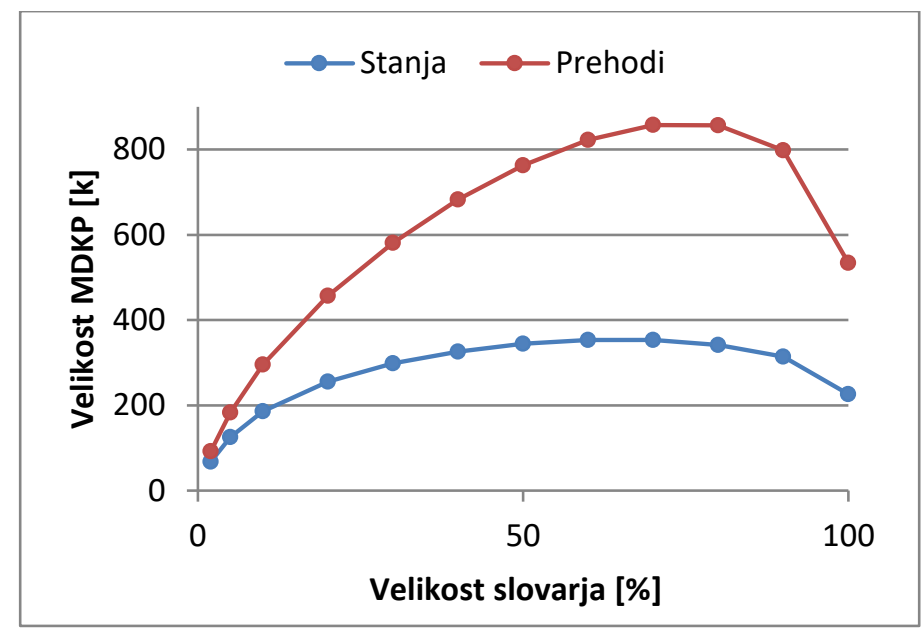

Slika 2: Odvisnost velikosti MDKP od velikosti slovarja izgovarjav.

Da bi ta pojav lahko lažje razložili, poglejmo enostaven primer, ki ponazarja vzroke zmanjšanja velikosti MDKP. Za primer vzemimo preprost slovar, katerega ključi ${ }^{1}$ so sestavljeni iz vseh možnih dvomestnih kombinacij treh črk $a, b$ in $c$. Na ta način dobimo 9 različnih ključev, in sicer: $a a, a b, a c, b a, b b, \ldots$ Zaradi enostavnosti naj bodo pripadajoče vrednosti kar enake ključem (tj. fonetični prepis je enak grafemskemu). MDKP za ta slovar prikazuje slika 3.

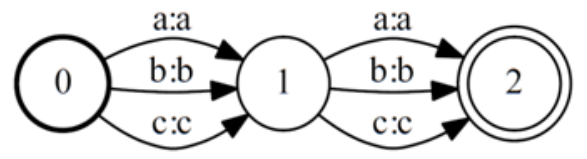

Slika 3: MDKP za slovar, katerega ključi so sestavljeni iz vseh možnih dvomestnih kombinacij treh črk a, b in c.

Iz slovarja nato odstranimo slovarski vnos $c c: c c$ ter ponovno zgradimo MDKP. Rezultat prikazuje slika 4. Opazimo lahko, da se je pri odstranitvi slovarskega

${ }_{1}$ Slovarski vnosi so sestavljeni iz para ključ, vrednost. Pri slovarju izgovarjav tako grafemski zapis predstavlja ključ, alofonski prepis pa vrednost. 
vnosa iz slovarja kompleksnost MDKP povečala, saj je za predstavitev zmanjšanega slovarja potrebno eno dodatno stanje ter dva dodatna prehoda.

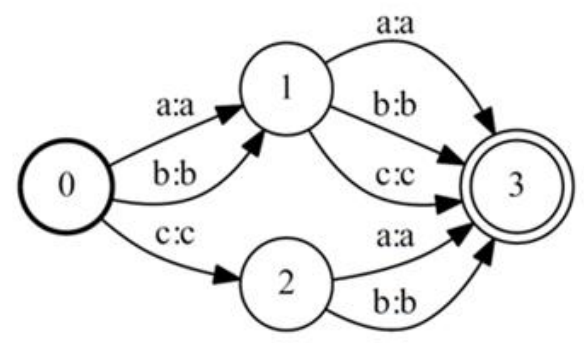

Slika 4: MDKP za enak slovar, kot ga predstavlja MDKP na sliki 2, pri čemer mu manjka slovarski vnos cc:cc.

Iz podanega primera je očitno, da je možno predstaviti večji slovar (ki v danem primeru vsebuje tudi vnos cc:cc) z manjšim MDKP kot manjši slovar (ki vnosa cc:cc ne vsebuje). Torej je možno, da z dodajanjem besed v slovar MDKP dejansko zmanjšamo, kot je to pokazano na na sliki 1.

\subsection{Vpliv pregibnih oblik na velikost slovarja izgovarjav}

$\mathrm{V}$ naslednjem poskusu smo se posvetili predvsem vplivu prisotnosti oz. odsotnosti pregibnih oblik lem besed v slovarju izgovarjav na velikost MDKP. Naša hipoteza je namreč bila, da na obrat trenda rasti MDKP vpliva prav prisotnost oz. neprisotnost pregibnih oblik $\mathrm{v}$ slovarju in da manjkajoče pregibne oblike pri manjših slovarjih povečujejo njihovo relativno kompleksnost oziroma velikost končnega pretvornika.

Da bi pokazali, da to velja, smo iz slovarja izgovarjav SI-PRON ponovno tvorili 11 naraščajoče velikih podslovarjev z naključnim izbiranjem, vendar pa smo v tem primeru naključno izbirali le leme besed, nato pa smo v podslovar vključili še vse pripadajoče pregibne oblike. Za vse podslovarje smo nato ponovno zgradili MDKP. Rezultate prikazuje slika 5. Iz grafa je razvidno, da velikost MDKP narašča sorazmerno z velikostjo slovarja in da tokrat ne pride do obrata pri trendu rasti. Iz tega lahko sklepamo, da so slovarji, ki so jim odstranjene 
prav vse pregibne oblike iste leme, predstavljeni kvečjemu z manjšimi MDKP. Kar pa ne velja (prvi primer z obratom trenda rasti), če v slovarju manjkajo pregibne oblike istih besednih lem. To potrjuje našo hipotezo, da posamezne manjkajoče pregibne oblike v slovarju lahko povečujejo kompleksnost oziroma velikost MDKP.

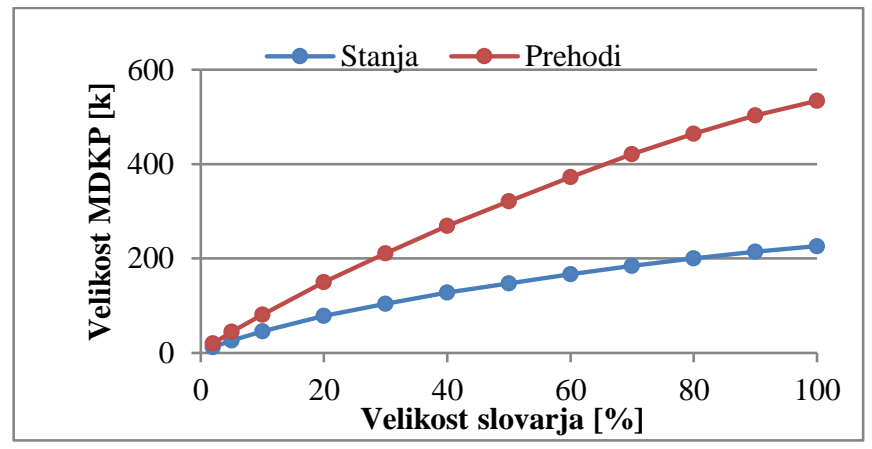

Slika 5: Odvisnost velikosti MDKP od velikosti slovarja izgovarjav.

Podana ugotovitev napeljuje na sklep, da je danim slovarjem izgovarjav smiselno dodati dodatne besede (denimo vse pregibne oblike lem), tudi če jih za dano področje uporabe morda ne potrebujemo, saj lahko s tem zmanjšamo kompleksnost in velikost končnih pretvornikov, ki jih uporabljamo za njihovo predstavitev. Na osnovi te ugotovitve smo prišli do zamisli končnih super pretvornikov, ki so predstavljeni v nadaljevanju.

\section{KONČNI SUPER PRETVORNIK (KSP)}

V prejšnjem poglavju smo pokazali, da lahko s pomočjo dodatnih, premišljeno izbranih vnosov besed $\mathrm{v}$ slovar zmanjšamo kompleksnost končnih pretvornikov. Pojavi pa se vprašanje, katere besede naj dodamo v slovar, da res zmanjšamo kompleksnost končnega pretvornika, še posebej $\mathrm{v}$ primeru obsežnih izvirnih slovarjev.

V ta namen smo poskusili preoblikovati MDKP tako, da bi ta sprejel in pretvoril nove besede. To lahko dosežemo z združevanjem njegovih stanj. Če bi, na 
primer, pri končnem pretvorniku na sliki 4 združili stanji 1 in $2 \mathrm{v}$ eno stanje, bi dejansko kot rezultat pridobili končni pretvornik, ki je podan na sliki 3. Slednji pa poleg osnovnih slovarskih vnosov, ki ne vsebuje vnosa $c c: c c$, dodatno sprejme ta manjkajoči vnos. Združevanje stanj MDKP torej dejansko lahko povzroči, da zmanjšani MDKP sprejme in pretvori dodatne besede, ki niso v izvirnem slovarju. Končni pretvornik na sliki 3 lahko torej razumemo kot končni super pretvornik saj ne sprejme in pretvori le besed iz izvirnega slovarja, ampak dodatno tudi manjkajoči slovarski vnos $c c$ :cc. Končni pretvornik na sliki 3 je torej svojevrsten »nad « pretvornik pretvornika na sliki 4. Izraz super končni pretvornik uporabljamo po analogiji iz teorije množic, kjer nadmnožicam (ki vsebujejo dano podmnožico) angleško pravimo tudi »super sets«.

Pojavi se vprašanje, katera stanja smemo združevati, da dosežemo opisani učinek in pri tem ne pokvarimo drugih pomembnih lastnosti končnega pretvornika, ki predstavlja dani izvirni slovar. Po študiji različnih primerov smo prišli do spoznanja, da je dopustno združevati le tista stanja, ki zadostijo naslednjima dvema ključnima pogojema:

- pridobljeni zmanjšani končni pretvornik mora ostati determinističen in

- pridobljeni zmanjšani končni pretvornik mora sprejemati vse besede prvotnega slovarja ter za te sprejete besede še vedno oddati pravilne pripadajoče fonetične pretvorbe.

Da bi zadostili omenjenima pogojema, smo s premislekom določili pravila, ki dovoljujejo združevanje le tistih stanj, ki imajo točno določene lastnosti. Takšna stanja smo poimenovali združljiva stanja. Pravila, ki opredelijo dve stanji za združljivi, in ki izpolnjujeta omenjena pogoja, so naslednja.

- Če je eno od obeh stanj končno stanje, stanji ne smeta imeti izhodnih prehodov s praznimi vhodnimi simboli oz. $\varepsilon$ simboli. Rezultat združevanja takšnih dveh stanj je sicer lahko nedeterministični končni 
pretvornik.

- Stanji nimata izhodnih prehodov z enakimi vhodnimi simboli ter različnimi izhodnimi simboli.

- Stanji nimata izhodnih prehodov z enakimi vhodnimi simboli ter enakimi izhodnimi simboli, ki prehajajo v različna naslednja stanja, ki so tudi nezdružljiva.

Da bi lahko opredelili dve stanji za združljivi, je potrebno preveriti vse tri zgornje pogoje, kar pa je v praksi lahko problematično, saj je preverjanje združljivosti vseh možnih stanj zaradi vsebovane rekurzivnosti (zadnje pravilo), ki je lahko tudi ciklična, zelo zahtevno. Zato smo zadnji pogoj poenostavili, in sicer:

- stanji nimata izhodnih prehodov z enakimi vhodnimi simboli ter enakimi izhodnimi simboli, ki prehajajo v različna naslednja stanja.

Zaradi poenostavitve zadnjega pogoja nekaterih sicer združljivih stanj ne moremo več odkriti, vendar so poskusi pokazali, da to zanemarljivo vpliva na končno velikost pridobljenega KSP (Golob, 2014).

Končne super pretvornike torej gradimo tako, da najprej zgradimo MDKP za dani vhodni slovar, nato pa pričnemo izvajati postopke nadaljnjega združevanja vseh stanj, ki se v skladu s podanimi pravili opredelijo za združljiva. Za vsako stanje je bilo potrebno preveriti, ali je združljivo s katerim koli drugim stanjem. Ker nekatera stanja postanejo združljiva šele, ko združimo druga sosednja stanja, je iskanje združljivih stanj potrebno izvesti v več iteracijah.

\section{PREDSTAVITEV SLOVARJA IZgOVARJAV S KSP}

Za slovar izgovarjav SI-PRON smo najprej zgradili MDKP s pomočjo odprtokodnega orodja OpenFST (Allauzen in dr., 2007), nato pa smo s postopkom, ki smo ga opisali v prejšnjem poglavju, zgradili še KSP. Tabela 1 prikazuje število stanj in prehodov MDKP in KSP. Opazimo lahko, da smo velikost MDKP uspeli zmanjšati za približno $20 \%$. 


\begin{tabular}{l|l|l|l|r}
\hline & & MDKP & \multicolumn{1}{l|}{ KSP } & Redukcija \\
\hline $\begin{array}{l}\text { En izhodni } \\
\text { simbol }\end{array}$ & Stanja & 226.363 & 172.833 & $23,6 \%$ \\
\cline { 2 - 5 } & Prehodi & 534.061 & 428.114 & $19,8 \%$ \\
\hline
\end{tabular}

Tabela 1: Redukcija števila stanj in prehodov pri gradnji KSP iz MDKP.

Čeprav lahko s KSP vnose v slovarju predstavimo z manjšim KP kot v primeru MDKP, pri tem izgubimo informacijo o tem, ali je sprejeta in pretvorjena beseda dejansko vsebovana v izvirnem slovarju. Tako se lahko zgodi, da KSP sprejme besedo, ki je morda slovnično pravilna, vendar ni bila vsebovana v slovarju. V tem primeru je lahko oddan alofonski prepis tudi napačen. V naslednjem poskusu smo ocenili napako, ki nastane, če za predstavitev vnosov slovarja namesto MDKP uporabimo KSP.

\subsection{Ocena verjetnosti napake KSP pri pretvarjanju izvenslovarskih besed}

Ker pri uporabi KSP izgubimo informacijo o tem, ali je sprejeta in pretvorjena beseda vsebovana v slovarju, so lahko besede, ki niso del slovarja, pretvorjene v napačen fonetični prepis. Če bi takšno informacijo imeli, bi lahko takšne besede namesto s KSP v fonetični prepis pretvorili s pomočjo drugih postopkov, na primer s pomočjo strojnega učenja.

Da bi ocenili verjetnost napake, ki jo na ta način naredimo, smo slovar SI-PRON naključno razdelili v dva podslovarja, pri čemer je prvi vseboval 90 \% besed, drugi pa preostalih 10 \% besed in je služil kot testni del. Za prvi del smo zgradili MDKP ter KSP. Rezultate gradnje prikazuje tabela 2.

\begin{tabular}{l|r|r|r}
\hline & \multicolumn{1}{|c|}{ MDKP } & \multicolumn{1}{c}{ KSP } & \multicolumn{1}{c}{ Redukcija } \\
\hline Stanja & 315.191 & 190.842 & $39,5 \%$ \\
\hline Prehodi & 800.026 & 478.315 & $40,2 \%$ \\
\hline
\end{tabular}

Tabela 2: Rezultati gradnje MDKP in KSP za pod-slovar, ki je vseboval $90 \%$ vnosov slovarja izgovarjav SI-PRON.

Opazimo lahko, da je tokrat zmanjšanje števila stanj in prehodov precej večje 
kot v primeru celotnega slovarja in je glede na MDKP približno 40 \%. Poleg tega je končno število stanj in prehodov manjše kot v primeru gradnje MDKP za celotni slovar. Iz tega lahko sklepamo, da je gradnja KSP še posebej smiselna, ko v podslovarju niso vsebovane vse pregibne oblike.

Nadalje smo grafemske zapise 124.099 slovarskih vnosov besed iz testnega dela slovarja dali na vhod zgrajenega KSP. Za grafemske zapise, ki jih je KSP sprejel, smo spremljali, če se pri tem oddani alofonski prepis ujema $\mathrm{z}$ alofonskim prepisom pripadajočega slovarskega vnosa. Rezultate prikazuje tabela Tabela . Pravilne sprejete vnose predstavljajo tisti slovarski vnosi, pri katerih je KSP oddal pravilen alofonski prepis.

\begin{tabular}{l|r}
\hline St. vseh testnih vnosov/besed & 124.099 \\
\hline Nesprejeti testni vnosi (zavrnjene besede) & 10.190 \\
\hline Sprejeti testni vnosi (pravilno pretvorjeni) & 106.698 \\
\hline Sprejeti testni vnosi (napačno pretvorjeni) & 7.211 \\
\hline
\end{tabular}

Tabela 3: Tabela prikazuje število sprejetih in nesprejetih besed oz. grafemskih zapisov slovarskih vnosov testnega slovarja, ko te damo na vhod KSP.

Bolj pregledno razmerja med posameznimi skupinami slovarskih vnosov prikazuje slika 9 .

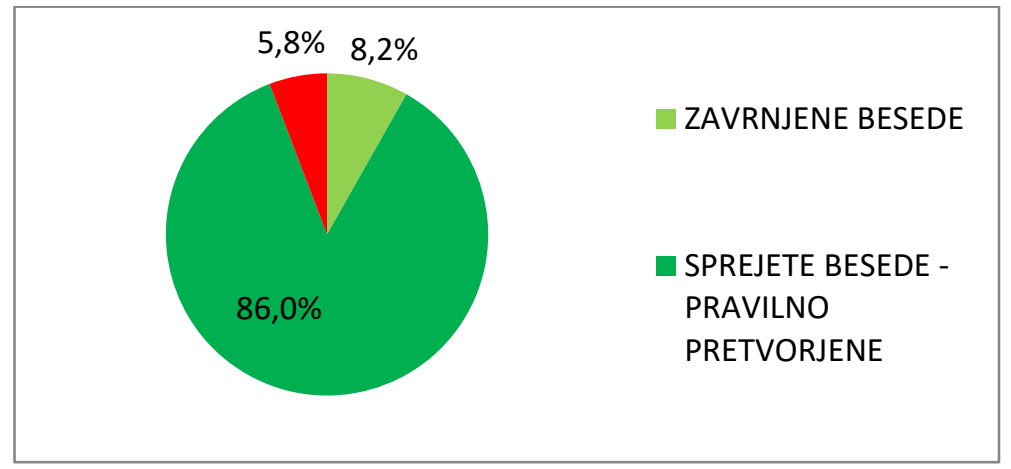

Slika 6: Razmerja med nesprejetimi ter sprejetimi vnosi, med katerimi nadalje ločimo tiste, za katere je bil oddani alofonski prepis bodisi pravilen bodisi napačen.

Iz rezultatov lahko razberemo, da je delež sprejetih in pretvorjenih besed kar 
91,8 \%. Pri tem je pomembno upoštevati, da ti vnosi niso bili vsebovani v slovarju izgovarjav, iz katerega smo zgradili KSP. Od sprejetih vnosov pa je delež tistih, za katere je KSP oddal napačen alofonski prepis, le 6,7 \%. To je rezultat, ki dosega in presega najboljše metode za samodejno grafemskofonemsko pretvorbo za slovenski jezik.

Pri podanih rezultatih pa moramo upoštevati dejstvo, da so bile testne besede (10 \% izhodiščnega slovarja) izbrane povsem naključno. Zato so se lahko tako v učnem kot tudi testnem delu slovarja nahajale pregibne oblike besed istih besednih lem. To pomeni, da so bile lahko med testnimi besedami tudi besedne oblike, ki so bile do manjših pregibnih sprememb v končnicah podobne katerim od besed v učnem delu slovarja. To pomaga razložiti razmeroma visok delež sprejetih in pravilno pretvorjenih izvenslovarskih besed.

Zato smo se odločili izvesti še en poskus, pri katerem smo 10 \% testnih besed iz slovarja izbrali tako, da smo najprej naključno izbrali besedne leme in nato $\mathrm{v}$ testni del slovarja preselili vse pregibne oblike, ki so pripadale izbranim lemam. V tem primeru gre namreč pričakovati, da testne izvenslovarske besede nimajo podobnih besed v učnem delu slovarja, ki smo ga uporabili pri gradnji KSP.

Po izvedbi poskusa s takšno razdelitvijo slovarja smo dobili rezultat, ki ga prikazuje graf na sliki 10. Vidimo, da je tokrat KSP sprejel le še 42,3\% izvenslovarskih besed, od teh je bilo pravilno pretvorjenih kar $85 \%$ besed, kar je še vedno primerljivo $s$ trenutno najuspešnejšimi samodejnimi metodami za slovenski jezik, ki se uporabljajo na tem področju. Pri samodejnih pretvornikih za slovenski govorjeni jezik je točnost pretvorbe odvisna predvsem od točnosti napovedovanja naglasnega mesta in doseženi delež napak pri tovrstnih pretvornikih je celo nekaj višji od 15 \% (Golob, 2009). 


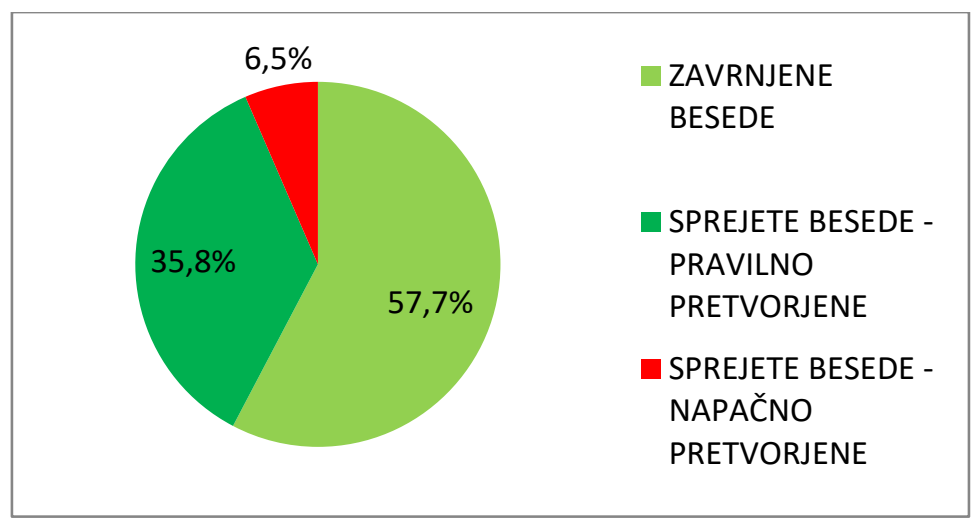

Slika 7: Razmerja med nesprejetimi ter sprejetimi vnosi, med katerimi nadalje ločimo tiste, za katere je bil oddan alofonski prepis bodisi pravilen bodisi napačen.

Razmeroma visok delež zavrnjenih besed se prav tako lahko šteje za pozitiven rezultat, saj lahko za zavrnjene besede še vedno uporabimo uveljavljene postopke za samodejno grafemsko-fonemsko pretvorbo.

\section{ZAKLJUČEK}

V članku je predstavljen nov tip končnih pretvornikov, ki smo jih poimenovali končni super pretvorniki (KSP). Ti poleg besed iz danega slovarja izgovarjav sprejemajo in v glavnem tudi pravilno pretvorijo še nekatere druge besede, ki niso zastopane v izvornem slovarju, t. i. izvenslovarske besede. Poglavitni namen uvajanja KSP pa je bil predvsem pridobitev čim bolj zgoščene in učinkovite predstavitve slovarjev izgovarjav za potrebe sintetizatorjev in razpoznavalnikov govora, ki jih želimo implementirati v vgrajenih sistemih z omejenimi pomnilniškimi in računskimi zmožnostmi.

Pokazali smo, da lahko pri predstavitvi slovarja izgovarjav s KSP število stanj in prehodov zmanjšamo za vsaj $20 \%$, ko so za vsebovane leme v slovarju izgovarjav prisotne tudi vse pripadajoče pregibne oblike besed, oziroma za kar $40 \%$ v primeru, ko v slovarju niso vsebovane vse pregibne oblike besednih lem. Ker KSP sprejemajo tudi druge, neznane izven-slovarske besede, za katere 
lahko oddajo napačen izhodni niz oz. jih napačno pretvorijo v alofonski zapis, so KSP uporabni predvsem v aplikacijah, kje ne potrebujemo informacije o tem, katere vhodne besede so vsebovane $\mathrm{v}$ danem slovarju izgovarjav, ampak le zagotovilo, da se bodo vse besede iz danega slovarja pravilno pretvorile $\mathrm{v}$ ustrezen alofonski zapis.

Za slovarje izgovarjav, ki jih navadno uporabljamo pri sintezi govora, si želimo, da pokrivajo čim večji delež vseh možnih besed, saj prav uporaba slovarjev omogoča najvišjo stopnjo točnosti pri njihovi grafemsko-fonemski pretvorbi. Ker pa se naravni jeziki nenehno spreminjajo in dopolnjujejo, navadno ne pričakujemo, da s slovarjem izgovarjav pokrijemo res prav vse možne besede danega jezika za dano področje uporabe. Zato lahko dane slovarje izgovarjav vedno predstavimo s predlaganimi končnimi super pretvorniki, pri čemer bo ta pri izven-slovarskih besedah sicer izvedel tudi kakšno napačno pretvorbo $\mathrm{v}$ fonetični zapis, vendar bo delež napak pri tej pretvorbi razmeroma nizek in primerljiv oziroma celo manjši od deleža napak pri uporabi namenskih samodejnih grafemsko-fonemskih pretvornikov.

\section{ZAHVALA}

Raziskovalno delo prvega avtorja je delno financirala Evropska unija iz evropskega socialnega sklada ter sklada za regionalni razvoj $\mathrm{v}$ okviru Operativnega programa krepitve regionalnih razvojnih potencialov za obdobje 2007 do 2013, po pogodbi št. P-MR-10/94.

\section{LITERATURA}

Allauzen, C., Riley, M., Schalkwyk J., Skut, W., Mohri M. (2007), OpenFst: A General and Efficient Weighted Finite-State Transducer Library. Proceedings of the 12th International Conference on Implementation and Application of Automata (CIAA 2007). Lecture Notes in Computer Science, Prague, Springer-Verlag, Heidelberg, Germany, 4783: 11-23. 
Daciuk, J., Piskorski, J., Ristov, S. (2011). Natural Language Dictionaries Implemented as Finite Automata. Scientific Applications of Language Methods. London: Imperial College Press, World Scientific Publishing.

Golob, Ž. (2009). Samodejno določanje mesta besednega naglasa pri sintezi slovenskega govora. Diplomsko delo, Fakulteta za elektrotehniko, Univerza v Ljubljani.

Golob, Ž., Žganec-Gros, J., Žganec, M., Vesnicer, B., Dobrišek, S. (2012). FSTBased Pronunciation Lexicon Compression for Speech Engines. International Journal of advanced robotic systems, 9: 2011.

Golob, Ž. (2014). Zmanjševanje odvečnosti končnih pretvornikov za samodejno sintezo govora v vgrajenih sistemih. Doktorska disertacija, Fakulteta za elektrotehniko, Univerza v Ljubljani.

Gros, J., Mihelič, F. (1999). Acquisition of an Extensive Rule Set for Slovene Grapheme-to-Allophone Transcription. Proceedings 6th European Conference on Speech Communication and Technology. September 59. 1999. Eurospeech 1999. Budapest, 5: 2075-2078.

Hellis, T. (2004). On minimality and size reduction of one-tape and multitape finite automata. Doktorska disertacija.

Lucchesi, C., Kowaltowski, T. (1993). Applications of Finite Automata Representing Large Vocabularies. Software-Practice \& Experience, 23: 15-30.

Mohri, M. (1994). Compact Representations by Finite-State Transducers. 32nd Meeting of the Association for Computational Linguistics (ACL '94). Proceedings of the Conference. Las Cruces. NM, pp. 204-209.

Mohri, M. (1997). Finite-State Transducers in Language and Speech Processing. Computational Linguistics, 33: 269-311.

Ristov, S. (2005). LZ Trie and Dictionary Compression. Journal Software- 
Practice \& Experience, pp. 445-465.

Rojc, M., Kačič Z. (2007). Time and Space-Efficient Architecture for a CorpusBased Text-to-Speech Synthesis System. Speech Communication. 49: 230-249.

Rojc, M., Mlakar, I. (2011). Multilingual and Multimodal Corpus-Based Textto-Speech System - PLATTOS. Ipšić I. (ur.). Speech and Language Technologies. Rijeka: InTech, 2011, str. 129-154.

Šef, T., Gams, M. (2004). Data mining for creating accentuation rules, Applied Artificial Intelligence, 17: 395-410.

Zemljak, M., Kačič, Z., Dobrišek, S., Gros, J., Weiss, P. (2002). Računalniški simbolni fonetični zapis slovenskega govora. Slavistična revija, 50: 159-169.

Žganec-Gros, J., Cvetko-Orešnik, V., Jakopin, P. (2006). SI-Pron Pronunciation Lexicon: A New Language Resource for Slovenian. Informatica, 30: 447-452. 


\section{A COMPACT REPRESENTATION OF PRONUNCIATION LEXICONS USING FINITE- STATE SUPER TRANSDUCERS}

Computer models based on finite-state transducers are well suited for compact representations of pronunciation lexicons that are used both in speech synthesis as well as in speech recognition. In this paper, we present a finite-state super transducer, which is a new type of finite state transducer that allows the representation of a pronunciation lexicon with fewer states and transitions than using a conventional minimized and determinized finite-state transducer. A finite-state super transducer is a deterministic transducer that can, in addition to the words comprised in the pronunciation lexicon, accept some other, out-ofdictionary words as well. The resulting allophone transcription for these words can be erroneous, but we demonstrate that such errors are comparable to the performance of state-of-the-art methods for grapheme-to-phoneme conversion. The procedure for building finite-state super transducers and a validation of their performance is demonstrated on the SI-PRON pronunciation lexicon. In addition, we also analyze several properties of finite-state transducers with respect to their minimum size obtained by their determinization and minimization. We show that for highly inflected languages their minimum size begins to decrease when the number of words in the represented pronunciation dictionary reaches a certain threshold.

Keywords: speech synthesis, pronunciation dictionary, finite-state transducers 
To delo je ponujeno pod licenco Creative Commons: Priznanje avtorstvaDeljenje pod enakimi pogoji 4.o Mednarodna.

This work is licensed under the Creative Commons Attribution-ShareAlike 4.0 International.

https://creativecommons.org/licenses/by-sa/4.o/

$$
\text { (c) } \underset{\mathrm{BY}}{\mathrm{BP}} \text { (?) }
$$

